\title{
CARACTERIZACIÓN DE LA LOCALIDAD DE EL SOBERBIO COMO CENTRO ESTRATÉGICO TURISTICO DE LA REGIÓN "DE LOS SALTOS DEL MOCONÁ"
}

\section{Miguel Ángel BARRETO / Evelyn R. ABILDGAARD}

Barreto, Miguel Ángel. Arquitecto, Magíster y Doctor en Antropología Social / Investigador adjunto del CONICET / Profesor titular de Desarrollo Urbano I (FAU-UNNE)/ Miembro del Instituto de Investigación y Desarrollo en Vivienda (IIDVI, FAU, UNNE).

Abildgaard, Evelyn R. Arquitecta (FAU-UNNE) / Adscripta a la cátedra de Desarrollo Urbano I (FAU-UNNE) / Becaria de Prestación de Servicio de la UNNE.

Palabras Clave: Desarrollo local, planificación regional, turismo.

Keywords: Local development, urban-regional planning, sustainable tourism.

\section{RESUMEN}

El presente trabajo toma como caso de estudio una localidad de la provincia de Misiones para analizar en el marco de su región de pertenencia las potencialidades que presenta para el desarrollo local a través de la Planificación Estratégica del Sector Turismo. Se trata de la localidad de El Soberbio, que representa el portal de acceso a una de las áreas turísticas más importantes de la provincia, la de los Saltos del Moconá. Esta área contiene un gran potencial, e integra en la actualidad una de las regiones estratégicas de la planificación turística provincial; sin embargo, presenta también importantes carencias que debe superar. Aquí se analizan estas potencialidades y carencias. ${ }^{1}$

\section{ABSTRACT}

The National Tourism Act declares of national interest to the tourism as socioeconomic strategic activity for the development. Based on the guidelines from the Federal Strategic Plan for Sustainable Tourism, the province of Misiones elaborated the Sustainable Tourism Strategic Plan, with the aim to generate basic conditions for the socioeconomic development, across the income of the tourism. This work studies the small city El Soberbio as the gateway to one of the regions with the greatest potential of provincial tourism development, the Saltos del Moconá region. However, it has lacks in social matter, land use, equipment and services. Here these deficits are analyzed to propose guidelines for the sustainable development. 


\section{OBJETIVOS}

El objetivo general de este trabajo es analizar y caracterizar la región denominada "de los Saltos del Moconá", como consecuencia de la aplicación de la regionalización basada en criterios de promoción turística, y en particular, detectar el rol que desempeña la localidad de El Soberbio como principal centro turístico de la región señalada y analizar el carácter de los recursos turísticos de la región y el tipo de activo o de capital que representan para el desarrollo de la localidad y de la región, para caracterizar su grado de sustentabilidad.

\section{INTRODUCCIÓN}

\section{El turismo como eje de la planificación del desarro- Ilo regional}

El concepto de región es bastante amplio y controvertido. Si bien se la puede definir como un espacio continuo, que tiene características diferentes de otros espacios con los que limita, no debe olvidarse que se trata siempre de un espacio dinámico sujeto a los cambios que generan todos los procesos sociales. DEMBICZ señala: "la región es un espacio socialmente construido -caracterizado por una estructura dinámica - diferente de esta que la rodea gracias a los rasgos del conjunto que crea" (DEMBICZ, 2005: 154).

La geografía tradicionalmente definió a la región desde un enfoque objetivo a partir de los elementos que la conforman. Desde esta perspectiva, la delimitación de una región se basa en el concepto de paisaje, a partir de la demarcación de áreas que presentan continuidad y similitud en sus componentes naturales (la topografía, el clima, la flora, la fauna, etc.). Al considerar también a las sociedades, hace referencia al concepto de paisaje "humanizado", e incorpora a la delimitación las características culturales y socioproductivas de la población. Desde la economía y la planificación, en cambio, se definió a la región desde un enfoque subjetivo, como un artificio intelectual en función de determinados fines (MARÍN, 2003). Según esta concepción, no existe un criterio único para definir una región; esta es siempre definida con una intención específica.

En nuestro contexto, en el campo de la planificación regional, la región es concebida y analizada a partir de sus potencialidades de desarrollo. Desde esta perspectiva, BOISIER ha definido a la región como un "Territorio organizado que contiene, en términos reales o en términos potenciales, los factores de su propio desarrollo" (COSSIO, 2003: 12). Además, la región (y sus localidades integrantes) es una parte de un todo, y debe ser considerada en relación con otras regiones y con el todo que lo contiene. Por lo tanto, las regiones y localidades deben analizarse como subsistemas abiertos, teniendo en cuenta tanto el sistema en su totalidad como las partes que lo componen, ya que la realidad de regiones y localidades es multiescalar. Así, las regiones y localidades se pueden caracterizar con referencia a sí mismas, con referencia a otras unidades del mismo conjunto, con referencia a la estructura del conjunto, con referencia a las subunidades y con referencia a las súper unidades (COSSIO, 2003: 9).

Partiendo de las fuertes desigualdades y contrastes que caracterizaron históricamente al territorio latinoamericano y nacional, el objetivo principal de la planificación regional en este contexto es promover el desarrollo socioeconómico a escala regional o local. Así, planificación regional se entiende en Latinoamérica - tanto en sentido económico como socio-político- como "planificación de desarroIlo regional". Desde esta perspectiva, la planificación regional es el instrumento del desarrollo regional (MERTINS, 2003: 7).

En la Argentina, el principal fundamento de la creación de regiones para el desarrollo se encuentra en el Art. 124 de la Constitución Nacional, el cual establece que "las provincias podrán crear regiones para el desarrollo económico y social y establecer órganos 
con facultades para el cumplimiento de sus fines y podrán también celebrar convenios internacionales en tanto no sean incompatibles con la política exterior de la Nación y no afecten las facultades delegadas al Gobierno federal o el crédito público de la Nación; con conocimiento del Congreso Nacional" (CONSTITUCIÓN NACIONAL, 1994).

En la escala regional, el desarrollo local es un proceso de transformación de la economía y de la sociedad local, orientado a superar las dificultades existentes, que busca mejorar las condiciones de vida de su población mediante una acción decidida y concertada entre los diferentes "agentes socioeconómicos locales, públicos y privados, para el aprovechamiento más eficiente y sustentable de los recursos endógenos existentes, mediante el fomento de las capacidades de emprendimiento empresarial local y la creación de un entorno innovador en el territorio" (COSSIO, 2003: 11).

A partir de estos fundamentos, y considerando que los atractivos naturales constituyen uno de los principales recursos con que cuenta la provincia de Misiones, el gobierno provincial, en el contexto de una política nacional, busca fomentar las actividades relacionadas con el turismo sustentable, a través de la planificación estratégica regional.

La Ley Nacional de Turismo N. ${ }^{\circ} 25997$ en su Art. 1. ${ }^{\circ}$ declara de interés nacional al turismo como actividad socioeconómica, estratégica y esencial para el desarrollo del país. Además expresa en el Art. 2. ${ }^{\circ}$ que el turismo se debe desarrollar en armonía con los recursos naturales y culturales, a fin de garantizar sus beneficios a las futuras generaciones. El turismo es un derecho social y económico de las personas dada su contribución al desarrollo integral en el aprovechamiento del tiempo libre y en la revalorización de la identidad cultural de las comunidades (LEY NACIONAL N. ${ }^{\circ} 25997,2005$ ).

A nivel nacional, el Plan Federal Estratégico de Turismo Sustentable Argentina 2016 tiene como misión promover las condiciones óptimas de competitividad que conduzcan al desarrollo equilibrado y sustentable del sector turístico argentino y a la mejora en la calidad de vida de residentes y visitantes. (PFETS, 2006). Dentro de sus objetivos se pueden citar los siguientes:

- Ambientales: implementar un modelo de desarrollo turístico respetuoso del ambiente natural que satisfaga las necesidades presentes, sin comprometer la capacidad de las generaciones futuras para satisfacer las propias.

- Socioculturales: lograr una mayor calidad de vida de los habitantes de la República Argentina, garantizando el respeto a la cultura, la identidad y los valores de las comunidades anfitrionas.

- De calidad: desarrollar una cultura de la mejora continua hacia la excelencia, basada en el compromiso de todos los actores y en la renovación de los métodos de gestión y producción, alineándolos a los objetivos estratégicos de la calidad.

- Socioeconómicos: propiciar la generación y distribución equilibrada de la renta turística interna y de los excedentes económicos internacionales generados por el turismo receptivo, creando al mismo tiempo oportunidades de desarrollo económico y social para las generaciones venideras.

Basándose en lineamientos establecidos por el PFETS (2012), la provincia de Misiones elaboró el Plan Estratégico Sustentable de Turismo, cuyo objetivo es "generar las condiciones básicas para lograr el desarrollo económico y social de las regiones que comprende, a través de los ingresos que genera el turismo, priorizando las acciones, obras e inversiones que permitan un avance real, optimizando los recursos disponibles. La propuesta de este plan se sustenta en procesos de planificación turística donde el eje está puesto también en la determinación de umbrales límites a las actividades tanto turístico recreativas como ambientales. Toda planificación de la actividad debe promover un turismo sostenible y responsable; debe ser beneficiosa para los turistas y para la comunidad receptora".

"El propósito del PEST es la identificación de proyectos prioritarios que dinamicen y a su vez fortalezcan el desarrollo turístico de ambas regiones de manera armónica y partiendo de la idea de trabajar corredores turísticos que integren y den fuer- 
Gráfico 1. a) Regiones Turísticas de Argentina; b) Mapa de Oportunidades de la Región Litoral. Fuente: Plan Estratégico Federal de Turismo (2006)
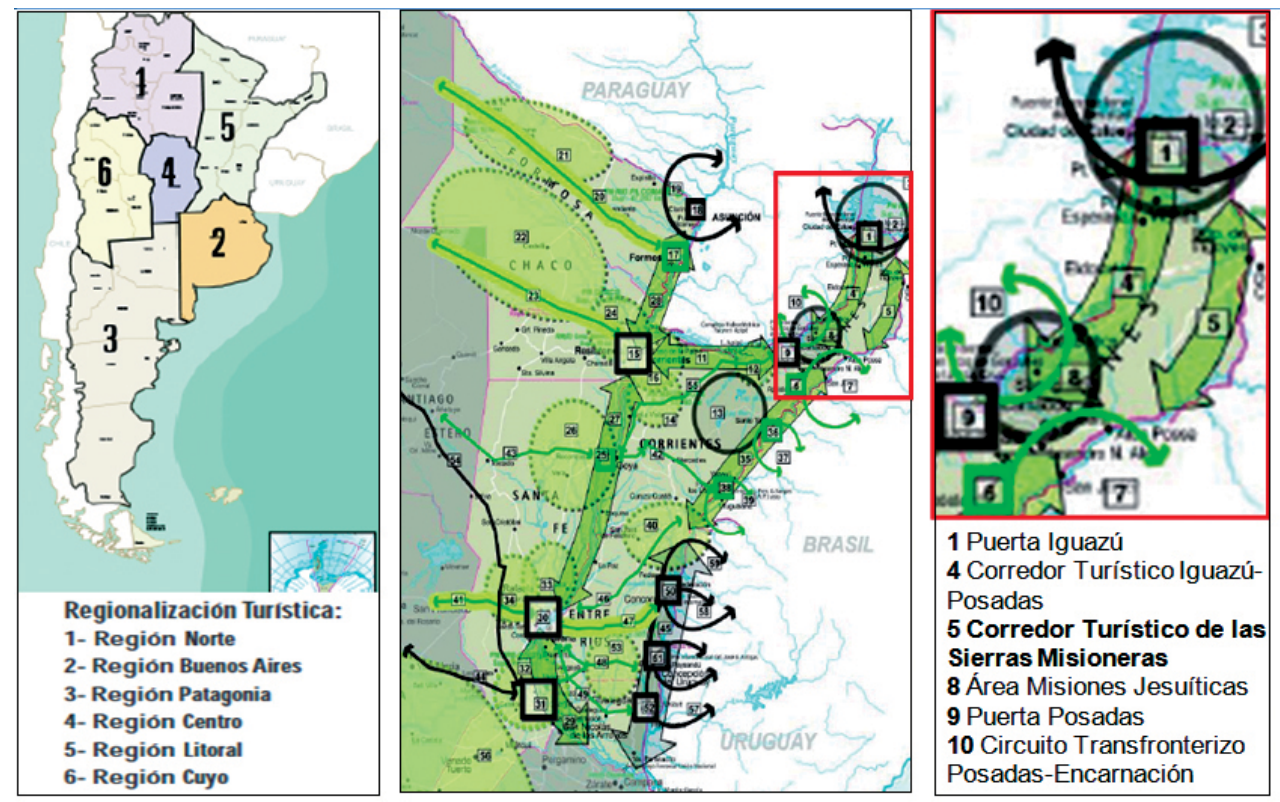

za a cada uno de los municipios integrantes de las regiones y sus áreas de influencia, como asi generar las condiciones necesarias para poder implementar las acciones recomendadas en la planificación estratégica sostenida" (PEST, 2012).

En este contexto, el presente trabajo se propone indagar las potencialidades y problemas que presenta la región de los Saltos del Moconá, y en particular la localidad de El Soberbio. Para ello se comienza analizando el encuadre general del Plan Federal de Turismo y la relación con la regionalización del Plan Provincial. Luego se caracterizan la región y la localidad (según las dimensiones jurídico-política, sociocultural, ambiental, económica y territorial), para diagnosticar las condiciones que posee esta última para constituirse en centro estratégico turístico de la región.

\section{RESULTADOS}

\section{La región de los Saltos del Moconá en el marco del Plan Federal Estratégico de Turismo Sustentable}

El Plan Federal Estratégico de Turismo Sustentable (PFETS) fue elaborado sobre la base de seis regiones que en conjunto conforman el Mapa Federal de Oportunidades Turísticas de la República Argentina, y en el cual se señalan corredores, áreas de uso turístico actual y áreas con vocación para el uso turístico que potenciar, puertas y circuitos transfronterizos. Misiones integra la Región Litoral (Gráfico 1. a) Regiones Turísticas de Argentina; b) Mapa de Oportunidades de la Región Litoral).

Los corredores turísticos son espacios geográficos o culturalmente homogéneos, vertebrados por rutas troncales de circulación, con atractores de jerarquía suficiente como para motivar flujos de demanda turística nacional e internacional. Por su escala pueden constituirse como unidades de planificación de desarrollo turístico regional y federal, y ser susceptibles de recibir regímenes de promoción turística y de fomento. El corredor puede incluir áreas menores vinculadas entre sí y también áreas fronterizas (PFETS, 2006).

El Plan Estratégico Sustentable (PEST) de Misiones toma como área que potenciar el Corredor de las Sierras Misioneras. Dicho plan cuenta con el apoyo financiero del Programa Multisectorial de Preinversión III, de la Dirección Nacional de Preinversión (DINAPREI), a través de un préstamo del Banco Interamericano de Desarrollo (BID).

A nivel nacional, la coordinación de su gestión se da a través de la Secretaría de Políticas Económicas perteneciente al Ministerio de Economía y Finanzas Públicas (MECON).

Las localidades que forman parte de las regiones establecidas por el PEST están situadas en la zona nordeste de la provincia, y limitan con la República Federativa de Brasil. Estas regiones son consideradas las de menor desarrollo relativo a nivel provincial. Además, por mucho tiempo, la conectividad con el resto de la provincia y el país fue muy débil, por lo tanto, las relaciones entre las localidades fronterizas de ambos países se vieron más fortalecidas que las internas.

Esta situación de "frontera viva" es también una característica para considerar al elaborarse los planes (Gráfico 2. Regiones turísticas establecidas en el Plan Estratégico Sustentable de Turismo). 
Gráfico 2. Regiones turísticas establecidas en el Plan Estratégico Sustentable de Turismo. Elaboración propia. Logos: PEST 2012

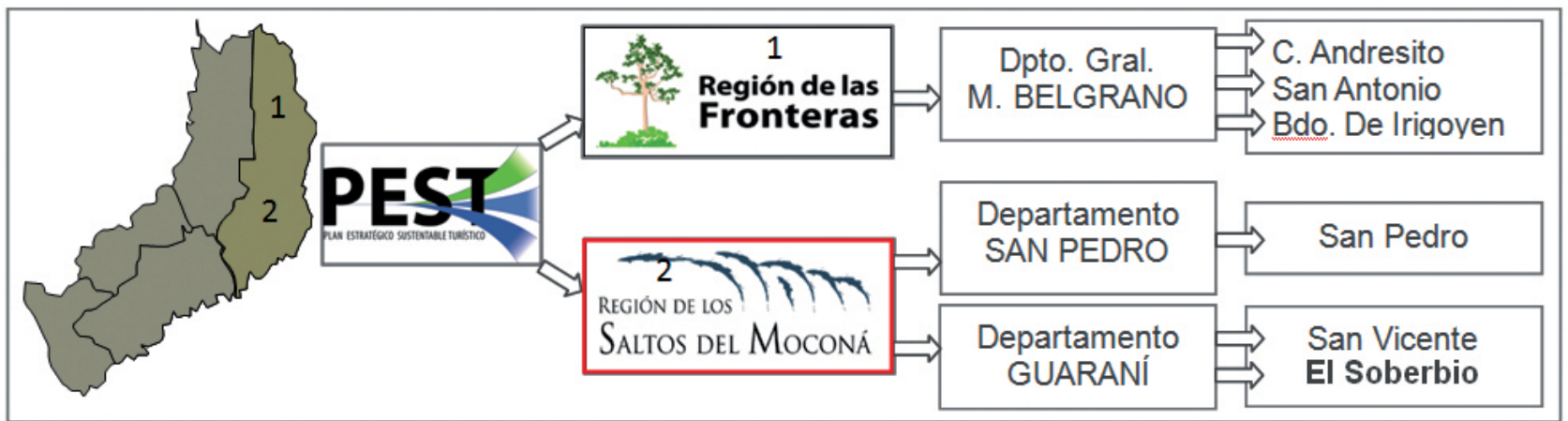

\section{Caracterización de la región de los Saltos del Moconá}

Sobre la base de una metodología de la complejidad (MORÍN, 1990; GARCÍA, 2006), se definieron cinco dimensiones analíticas:

\section{- Dimensión Jurídico-Política}

La provincia de Misiones está constituida por 75 municipios agrupados en 17 departamentos. La Región de los Saltos del Moconá comprende el departamento San Pedro, con su municipio homónimo, y el departamento Guaraní, formado por los municipios de San Vicente y El Soberbio, todos ellos municipios de Primera Categoría. Según la Constitución de la Provincia de Misiones, los municipios de primera categoría gozan de autonomía política, administrativa y financiera, desempeñan sus funciones con independencia de todo otro poder (Art. 161) y ejercen su gobierno a través de una rama ejecutiva y otra deliberativa (Art. 162). Además, pueden dictarse sus respectivas cartas orgánicas para su gobierno, de acuerdo con los principios contenidos en la Constitución Provincial (Art. 170).

De los tres municipios que forman la región, El Soberbio es el único que en la actualidad cuenta con Carta Orgánica Municipal. La provincia de Misiones requiere un mínimo de 10.000 habitantes para permitir su dictado. Actualmente solo ocho municipios de la provincia cuentan con dicha carta.

EL Art. 8 de la Carta Orgánica de El Soberbio hace referencia a las competencias del municipio en cuanto a la celebración de convenios con entidades privadas, reparticiones públicas nacionales, provinciales y municipales, así como también con municipios vecinos de países limítrofes, en materia de servicios públicos, con fines turísticos, culturales y deportivos (Inc. 5). También en cuanto al fomento de la actividad turística, a la reglamentación y fiscalización de sus servicios en todo el ejido municipal (Inc. 22). Es además competencia del municipio asegurar el derecho de los habitantes a disfrutar de un medio ambiente adecuado para el desarrollo de las personas, manteniendo y protegiendo el sistema ecológico y el paisaje median- te la utilización racional de los recursos naturales (Inc. 24), y efectuar el reconocimiento histórico del pueblo guaraní, declarando de interés municipal la preservación de su sistema social y cultural y alentando su participación en el proceso de desarrollo del municipio (Inc. 29, Carta Orgánica Municipal de El Soberbio, 1990). Por lo tanto, este artículo refleja la intención de fomentar el turismo local, respetando a los habitantes del municipio y protegiendo su ambiente mediante el aprovechamiento sustentable de los recursos naturales.

La reforma constitucional de 1994 promovió la descentralización administrativa, entendida como delegación de responsabilidades y de toma de decisiones del gobierno central a las provincias y municipios. A partir de ella, los gobiernos locales dispusieron de mayor independencia para ejecutar políticas. Sin embargo, este proceso no fue acompañado con la descentralización de recursos y la capacitación de los actores locales para encarar acciones propias de desarrollo. Los municipios de esta región disponen aún de una muy baja capacidad de gestión para la promoción del desarrollo local, como lo ponen en evidencia los indicadores que se analizan en los puntos siguientes.

\section{- Dimensión Socio-demográfica y Cultural}

Según datos censales de 2001 y 2010, los departamentos que integran la región en estudio han experimentado un incremento acelerado de población. En términos relativos, a nivel provincial el departamento que más crecimiento obtuvo en el período intercensal fue San Pedro (30,8 \%). Por otra parte, este es el departamento de menor densidad poblacional de la provincia. El Departamento Guaraní también tuvo un incremento relativo superior al promedio provincial, y revela que conjuntamente con San Pedro es una región que ha tenido un crecimiento acelerado de la población, con una dinámica que resulta superior al promedio de Misiones (Cuadro 1. Dinámica de la población de los departamentos de la Región Salto del Moconá. Período 2001- 2010). (Gráfico 3. Características demográficas de los departamentos de la provincia de Misiones). 
Cuadro 1. Dinámica de la población de los departamentos de la Región Salto del Moconá. Período 2001- 2010. Elaboración propia. Fuente: INDEC. CNPHV 2001 y 2010

\begin{tabular}{|l|l|l|l|l|l|l|}
\hline $\begin{array}{l}\text { Departa- } \\
\text { mento }\end{array}$ & $\begin{array}{l}\text { Población } \\
\text { 2001(hab.) }\end{array}$ & $\begin{array}{l}\text { Población } \\
\mathbf{2 0 1 0}(\text { hab.) }\end{array}$ & $\begin{array}{l}\text { Variación } \\
\text { Absoluta }\end{array}$ & $\begin{array}{l}\text { Variación } \\
\text { Relativa }(\%)\end{array}$ & $\begin{array}{l}\text { Superficie } \\
\left(\mathrm{Km}^{2}\right)\end{array}$ & $\begin{array}{l}\text { Densidad } \\
\left(\mathrm{hab} . / \mathrm{Km}^{2}\right)\end{array}$ \\
\hline Guaraní & 57.818 & 67.897 & 10.079 & 17,4 & 3.314 & 20,5 \\
\hline San Pedro & 23.736 & 31.051 & 7.315 & 30,8 & 3.407 & 9,1 \\
\hline MISIONES & 965.522 & 1.101 .593 & 136.071 & 14,1 & 29.801 & 37,0 \\
\hline
\end{tabular}

Gráfico 3. Características demográficas de los departamentos de la provincia de Misiones. Fuente: INDEC. Datos Censo Nacional de Población, Hogares y Viviendas. Año 2010.

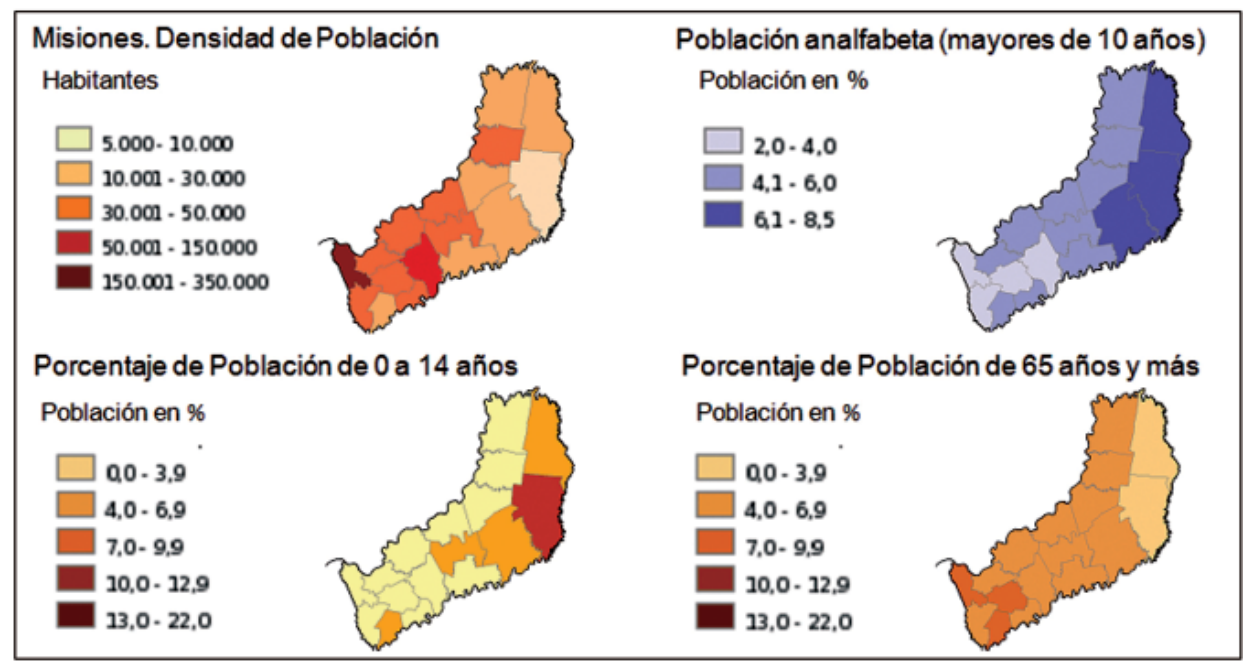

Cuadro 2. Población Urbana y Rural de los Municipios de la Región de los Saltos del Moconá). Elaboración propia. Fuente: INDEC. CNPHV 2010

\begin{tabular}{|l|l|l|l|l|l|l|}
\hline Municipio & $\begin{array}{l}\text { Zona } \\
\text { Urbana }\end{array}$ & $\begin{array}{l}\text { Zona Rural } \\
\text { Agrupada }\end{array}$ & $\begin{array}{l}\text { Zona Rural } \\
\text { Dispersa }\end{array}$ & $\begin{array}{l}\text { Total } \\
\text { Población } \\
\text { (habitantes) }\end{array}$ & $\begin{array}{l}\text { Población } \\
\text { Rural (\%) }\end{array}$ & $\begin{array}{l}\text { Densidad } \\
(\text { hab./Km }\end{array}$ \\
\hline El Soberbio & 5.065 & - & 17.833 & 22.898 & 77,88 & 20,5 \\
\hline San Vicente & 21.068 & 471 & 23.460 & 44.999 & 52,13 & 9,1 \\
\hline San Pedro & 10.397 & 1.840 & 18.814 & 31.051 & 60,59 & 37,0 \\
\hline Misiones & 812.554 & 54.389 & 234.650 & 1.101 .593 & 21,30 & \\
\hline
\end{tabular}

San Pedro es además el departamento con mayor porcentaje de población joven (de 0 a 14 años) de Misiones. La estructura de población de toda la región presenta características demográficas de bajo desarrollo relativo, esto es alta tasa de natalidad, menor porcentaje de población joven activa y de población mayor. La región de los Saltos del Moconá es la que concentra menor porcentaje de personas mayores de 65 años de la provincia.

Una de las causas de la disminución de la población joven activa se debe a la emigración que se produce a ciudades de otras regiones en busca de mayores posibilidades de trabajo, y porque esta región carece de instituciones de educación de niveles terciario y universitario.

Esta región cuenta además con los mayores índices de analfabetismo de la provincia (gráfico 3). En esta zona funcionan Escuelas de Jornada Completa y las Escuelas de Familias Rurales (EFA), las cuales constituyen un importante factor de integración sociocultural entre la población rural. Son significativas las diferencias cuantitativas entre la población urbana y rural de esta región, con un predominio de los habitantes rurales, incluso con valores superiores al promedio provincial. Este fenómeno se refleja a nivel de los municipios de los departamentos de la región. La población del Municipio de El Soberbio es de 22.898 habitantes, y el 77,88 $\%$ se asienta en zonas rurales, mientras que apenas el 22,12\% restante lo hace en la zona urbana (Cuadro 2. Población Urbana y Rural de los Municipios de la Región de los Saltos del Moconá).

La composición cualitativa de la población de esta región, fuera del área urbana, es también muy particular. La población rural está compuesta principalmente por familias de pequeños productores agrícolas, en su mayoría de origen brasileño, expulsados por el proceso de concentración de tierras destinadas al cultivo de soja en su país, o descendientes de inmigrantes alemanes, quienes habían llegado a otras zonas de Misiones, atraídos 
Gráfico 4. a) Corredor Verde y Áreas Protegidas; b) Reserva Yabotí y c) Ordenamiento Territorial según la Ley de Ordenamiento y Conservación de Bosques Nativos de Misiones. Fuente: a. DIAS LACAVA (2003). b.Secretaría de Ambiente y Desarrollo Sustentable de la Nación. c.Sistema de Información Ambiental de Misiones (2010).

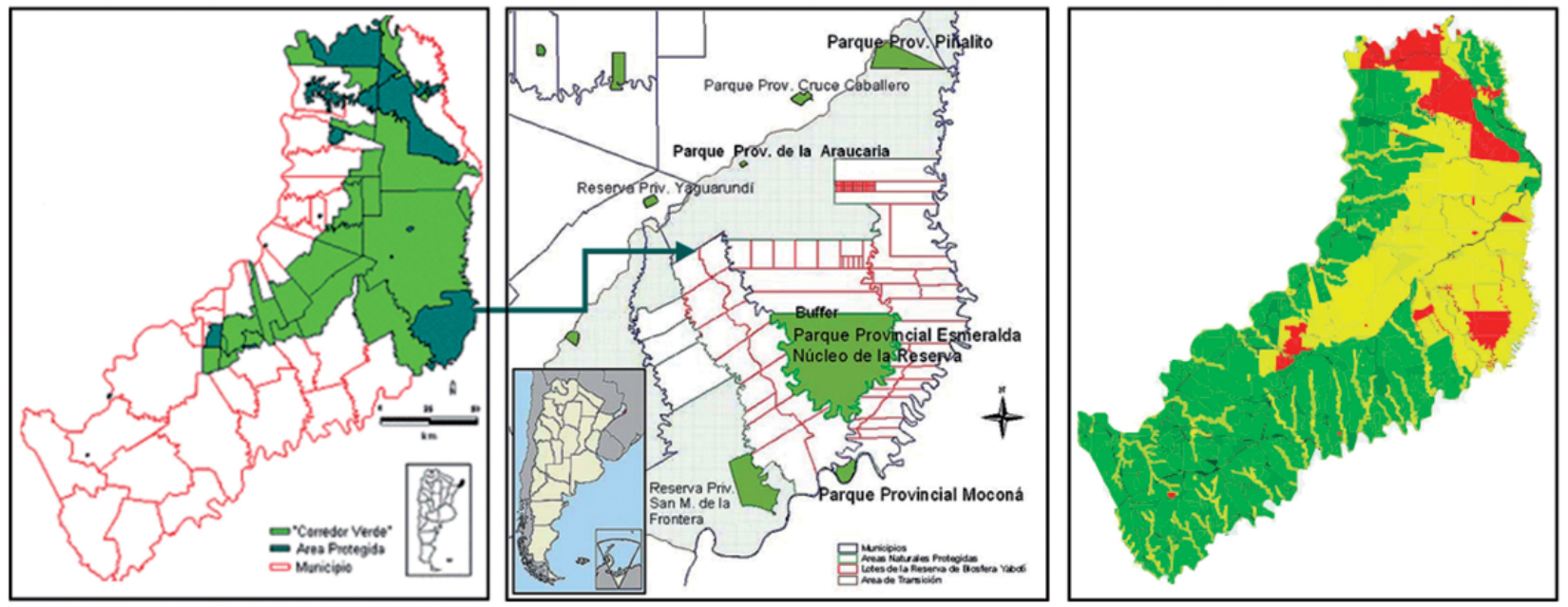

por las campañas de colonización de las primeras décadas del siglo $\mathrm{XX}$, y que luego se trasladaron hacia las márgenes del río Uruguay.

A lo largo del corredor que abarca tanto la región de los saltos como la de las fronteras, se encuentran aldeas del pueblo mbyá, perteneciente al grupo de los "monteses", que eran aquellos guaraníes que, refugiados en lo más profundo de la selva, se mantuvieron lejos del sometimiento de los conquistadores y de la evangelización de los jesuitas. Sus descendientes actuales conservan muchos elementos de aquella cultura tradicional, en especial el idioma guaraní, que hablan en un dialecto muy antiguo. Sus aldeas son pequeñas y están ubicadas en tierras privadas o fiscales. Las antiguas casas comunitarias ancestrales, denominadas malocas, fueron remplazadas por simples casas para cada familia. En los últimos años, la región ha comenzado a ser receptora de pobladores urbanos de otras provincias que se asientan en la zona con el fin de generar emprendimientos turísticos no tradicionales (como por ejemplo, las modalidades de ecoturismo, turismo rural o de aventura, etc.) A estos pobladores el PEST los mal denomina "rururbanos". 2

\section{- Dimensión Ambiental}

Gran parte de la Región de los Saltos del Moconá integra el denominado Corredor Verde de la Provincia de Misiones, creado por Ley 3631/99, a través de la cual se constituye una plataforma para el ordenamiento territorial y para la planificación bio-regional. Se definen tres núcleos (Parque Nacional Iguazú, Parque Provincial Urugua-í y la Reserva de Biósfera Yaboti) conectados mediante una red de bosques protectores y fajas ecológicas. Esta iniciativa busca preservar la biodiversidad.

La Reserva de Biosfera Yabotí (RBY) fue creada por Ley N. ${ }^{\circ} 3041$ de la Cámara de Diputados de la

[2 ] Una revisión de este concepto en: CARDOSO Y FRITSCHY (2012).
Provincia. Se encuentra ubicada en los municipios de San Pedro y El Soberbio. Cuenta con aproximadamente 253.773 ha. El relieve en su mayor parte está formado por serranías, habiendo en muchos casos pendientes muy pronunciadas. Las altitudes varían desde los 200 metros snm sobre el río Uruguay, hasta los 648 metros snm en el sector NE de la reserva. La RBY está constituida por 119 lotes, en su mayoría de propiedad privada. Quedan incluidos dentro de esta reserva el Parque Provincial Moconá y la Reserva de Esmeralda, ambos de dominio del Estado provincial. Al ser estas propiedades, en su mayoría, de dominio privado, están sometidas actualmente a distintos tipos de intervención, siendo el más importante el forestal de tipo selectivo. (Gráfico 4. a) Corredor Verde y Áreas Protegidas; b) Reserva Yabotí y c) Ordenamiento Territorial según la Ley de Ordenamiento y Conservación de Bosques Nativos de Misiones).

En diciembre de 2007, se sancionó la Ley Nacional N. ${ }^{\circ} 26331$ "De Presupuestos Mínimos para la Protección Ambiental de los Bosques Nativos", la cual obliga a las provincias a detener la deforestación hasta tanto no se establezca un ordenamiento territorial de los bosques nativos. En el año 2010 la provincia aprobó la Ley de Ordenamiento y Conservación de Bosques Nativos de Misiones. La norma establece, mediante criterios de sustentabilidad, tres categorías de ordenamiento: Categoría I (zona roja) comprende las áreas naturales protegidas con categoría de conservación, como parques y reservas provinciales. La Categoría II (zona amarilla) abarca los bosques nativos en propiedades privadas, tales como las reservas de usos múltiples, donde pueden desarrollarse aprovechamientos sustentables sin afectar la masa nativa, mientras que la Categoría III (zona verde) incluye áreas que pueden ser utilizadas para desarrollar actividades productivas, siempre y cuando sean sustentables y no afecten las áreas pobladas por comunidades guaraníes, especies en extinción y que no sean corredores bio- 
lógicos. La autoridad de aplicación de estas leyes ambientales es el Ministerio de Ecología y Recursos Naturales Renovables, cuya misión es la defensa del ambiente y ser contralor de la explotación racional de sus recursos naturales. Misiones es la única provincia argentina con un organismo de incumbencias ambientales y forestales de rango ministerial.

Dentro de la Región de los Saltos del Moconá, la mayor parte de las áreas naturales protegidas y bosques nativos se encuentra en San Pedro, mientras que San Vicente es el municipio con mayor superficie de áreas que pueden utilizarse para el desarrollo de actividades productivas sustentables. En el caso de El Soberbio, su territorio cuenta con aproximadamente el mismo porcentaje de áreas categorizadas como I y II, es decir, áreas protegidas y áreas destinadas a la realización de actividades productivas sustentables.

\section{- Dimensión Económica}

Los sectores productivos que se destacan en la región de los Saltos del Moconá son el maderero, el turístico y el tabacalero. En El Soberbio se desarroIla además la actividad esenciera, la cual implica el cultivo de hierbas aromáticas y su procesamiento tanto industrial como artesanal.

- Sector Maderero: dentro de la región, el epicentro de esta actividad es la localidad de San Vicente, la cual se caracteriza por tener gran cantidad de establecimientos, la mayoría en condiciones muy precarias, pero que a la vez cuenta con emprendedores forestales que están iniciando procesos de reconversión tecnológica. Son las pequeñas carpinterías familiares y los artesanos quienes presentan mayores dificultades para acceder al apoyo financiero. La escala de estos emprendimientos le ha dado a la actividad un perfil informal, caracterizado por el atraso tecnológico y las limitaciones en materia de gestión y desarrollo de productos. La comunidad local reclama la creación de un Centro Tecnológico de la Madera que acompañe al sector productivo mediante la formación de recursos humanos, asistencia técnica y capacitación.

- Sector Tabacalero: empresas multinacionales, a través de acopiadores locales, controlan la totalidad del proceso productivo. Este tipo de integración vertical se desarrolla mediante la modalidad de agricultura bajo contrato. Anualmente los acopiadores, subordinados a los requerimientos de las grandes tabacaleras, entablan relaciones contractuales con los productores primarios, quienes son propietarios $u$ ocupantes de pequeñas extensiones de tierra, emplean mano de obra familiar y el promedio de superficie que dedican al tabaco raramente supera las cinco hectáreas. Las empresas financian los insumos hasta la cosecha (materiales, fertilizantes, semillas, agroquímicos), y el productor vende la producción clasificada. Sin embargo, el productor se inserta en esta modalidad en condiciones asimétricas, ya que los insumos adelantados por las empresas poseen precios onerosos, lo que contrasta con los precios más bajos de estos en el mercado local (ROCCATAGLIATA, 2008).

- Actividad Esenciera: en El Soberbio se cultivan hierbas aromáticas, como el cedrón, espartillo, lemmon grass, menta japonesa y principalmente la citronela, la cual se desarrolla gracias al microclima que genera el río Uruguay. Estos cultivos difieren de otros, como el tabaco, por su sencillez, distancia de agrotóxicos e inversión mínima. A comienzos de los años 80, se contaba con 6000 hectáreas sembradas. Existían alrededor de 700 alambiques con una producción de 700 toneladas de aceites. La Sociedad Argentina de Productores Industriales de Aromáticos designa en 1980 a El Soberbio como Capital Nacional de las Esencias. En la década del 90, toda la plantación se exportaba; sin embargo, la mayor parte de las ganancias quedaba en manos de los acopiadores, lo que llevó a los productores a cambiar drásticamente de cultivo: el tabaco. En los últimos años se ha impulsado nuevamente el cultivo de hierbas aromáticas y la producción de esencias, a través de la Cooperativa Esenciera Río Uruguay. - Sector Turístico: este sector ha experimentado 
"Los atractivos paisajísticos y su proximidad a los Saltos del Moconá son factores que contribuyen al potencial que tiene la localidad de El Soberbio para constituirse en centro estratégico de su región de pertenencia; sin embargo, los servicios turísticos y los recursos humanos especializados aún no son suficientes."

un notable crecimiento en los últimos años, principalmente con la modalidad del denominado Turismo Alternativo. Según el estudio de Demanda de Destinos 2012-2013 (PEST 2012), realizado por el Ministerio de Turismo de la Provincia de Misiones, los Saltos del Moconá constituyen el tercer destino turístico de Misiones (28,8\%), precedido por las Cataratas del Iguazú $(92,1 \%)$ y las Reducciones de San Ignacio (45,4 \%). El Parque Provincial Moconá es una de las áreas protegidas que forman parte de la Reserva de Biosfera Yabotí, figurando en la lista de la UNESCO desde 1995. La región cuenta además con otros atractivos turísticos, como los saltos Tarumá, Rosa Mística y Golondrina, entre otros. A ellos también se suman las fiestas populares: en San Vicente se realiza la Fiesta Nacional de la Madera y además el Encuentro Regional de Tallistas. En El Soberbio el Festival Nacional de la Esencia y la Fiesta Provincial de la Citronela.

Según datos del PEST (2012), en el último año 257.400 turistas fueron a la región de los Saltos del Moconá, de los cuales 136.800 visitaron El Soberbio. Esta es la localidad más desarrollada de las tres que integran la región. Cuenta actualmente con 380 plazas hoteleras, mientras que en San Vicente existen 235 y en San Pedro 100. Las inversiones locales (hoteles, hosterías, cabañas, residenciales, campings) son en su mayoría de tipo familiar. En el caso de los denominados lodges, los emprendimientos se sitúan principalmente en áreas de reservas privadas y son, en general, de capitales extranjeros o nacionales, foráneos a la región. Operadores turísticos locales se organizan en una Cámara de Turismo. El rubro gastronómico está comenzando a desarrollarse.

La mayor deficiencia con que cuenta El Soberbio es el servicio de transporte público de pasajeros de larga distancia a nivel nacional, ya que este solamente llega hasta San Vicente. A nivel provincial existen algunas empresas que acceden a El Soberbio por la ruta provincial $N^{\circ} 13$, pero ninguna lo hace por la ruta costera $\mathrm{N}^{\circ}{ }^{2}$, pensada en el plan estratégico provincial como eje estructurador del corredor de las sierras misioneras. El paso fronterizo hacia la República Federativa de Brasil se realiza a través de balsas.

Los atractivos paisajísticos y su proximidad a los Saltos del Moconá son factores que contribuyen al potencial que tiene la localidad de El Soberbio para constituirse en centro estratégico de su región de pertenencia; sin embargo, los servicios turísticos y los recursos humanos especializados aún no son suficientes. Desde el punto de vista local, no se ha asumido todavía el rol que pudiera tener la localidad como centro estratégico turístico de la región.

\section{- Dimensión Territorial}

Las principales vías de acceso a la región de los Saltos del Moconá son la ruta nacional $\mathrm{N}^{\circ}{ }^{\circ} 14$ y la ruta provincial $\mathrm{N}^{\circ}{ }^{\circ}$ 2. Esta última, también conocida como "la ruta costera", tiene la particularidad de bordear el río Uruguay, lo cual permite apreciar el paisaje característico de la zona. En su primer tramo, hasta la localidad de El Soberbio, fue nombrada Juan Pablo II, y luego de atravesar dicha localidad pasa a denominarse Ruta Panorámica, culminando su recorrido en el Parque Provincial Moconá. Este último tramo de $76 \mathrm{~km}$ cuenta actualmente con seis miradores que tienen como objetivo brindar puntos panorámicos que permitan contemplar el entorno natural. La Dirección Provincial de Vialidad está a cargo de su construcción y mantenimiento. Esta ruta aún no dispone de los servicios suficientes de transporte, de equipamientos y de infraestructura como para constituirse en el eje estructurador del corredor de las sierras.

Dentro de la región, la ruta provincial $\mathrm{N} .^{\circ} 13$ (asfaltada) vincula a San Vicente con El Soberbio, mientras que las RP N. ${ }^{\circ} 15,16,21$ (terradas) conectan a los pueblos ribereños con la RN N. ${ }^{\circ} 14$. Estas rutas de tierra se utilizan para la extracción de la producción de la zona y constituyen la vía de 
Gráfico 5. Red vial de la región de los Saltos del Moconá. Fuente: Plan Estratégico Sustentable de Turismo 2012

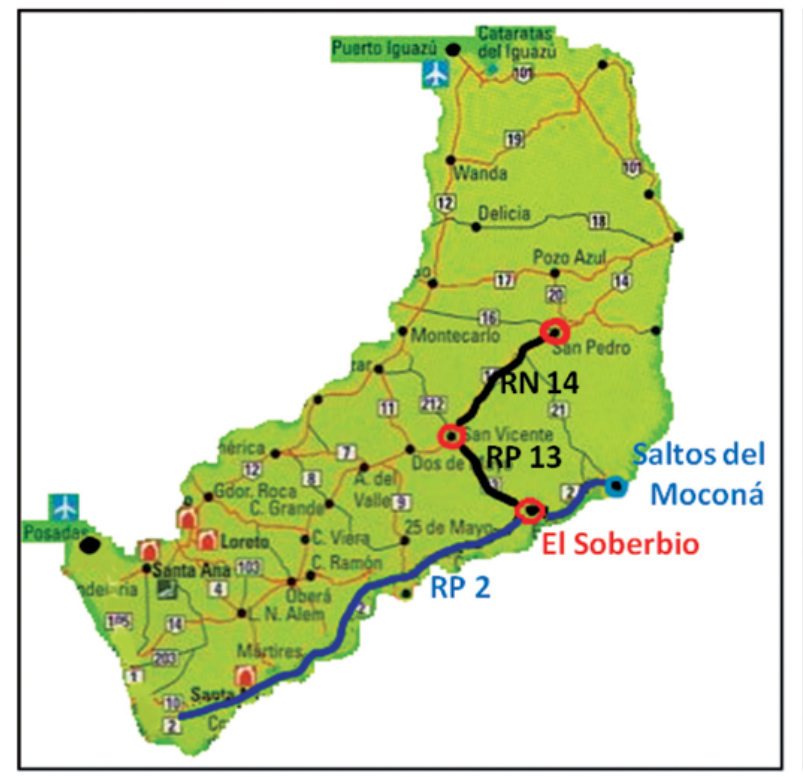

comunicación de las áreas rurales. Además son utilizadas por empresas turísticas para la realización de travesías turísticas. La ruta N. ${ }^{\circ} 15$ es la principal conexión vial con los pueblos originarios que habitan dentro de la Reserva de Biosfera Yabotí. (Gráfico 5. Red vial de la región de los Saltos del Moconá).

La región de los Saltos del Moconá se caracteriza por el predominio de la zona rural sobre la urbana. Cuenta con una superficie de $6721 \mathrm{~km}^{2}$ y una densidad de población de 29,6 hab/km². Tal como se ha mencionado en la dimensión socio-demográfica y cultural, solamente tres localidades superan los 2000 habitantes: San Pedro, El Soberbio y San Vicente. Esta última cumple el rol de nodo dentro de la región al articular las otras dos localidades mediante las rutas RN N. ${ }^{\circ} 14$ y RP N. ${ }^{\circ} 13$.

- El servicio de energía eléctrica, tanto en áreas urbanas como rurales es deficitario y provoca serios cortes en la provisión de la energía a las comunidades, principalmente en verano, con reiteradas bajas en la tensión de la corriente eléctrica. La capacidad de la red de transmisión y distribución de energía eléctrica en media tensión (LAM) es insuficiente para satisfacer la creciente demanda en toda la región y en los municipios.

- La infraestructura de alumbrado público actual presenta serias deficiencias, ya que en la mayoría de los casos es obsoleta. Las luminarias son antiguas y sobre la base de lámparas incandescentes de alto consumo de energía eléctrica. El mantenimiento lo realiza la empresa provincial EMSA con la provisión de materiales por parte de los municipios. Las avenidas de acceso, las calles principales y los espacios verdes de uso público no se encuentran debidamente mantenidos ni equipados, ni iluminados como para brindar mayor atractivo, seguridad y jerarquizar estos sectores. Un servicio de alumbrado público eficiente es un elemento que contribuye a mejorar la imagen de la ciudad.

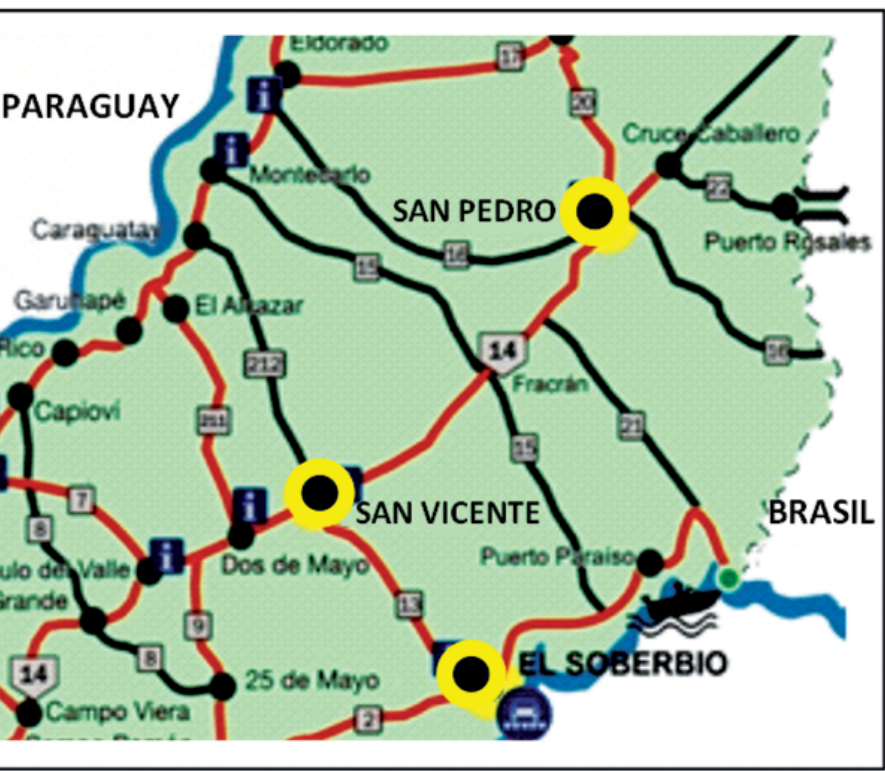

- En cuanto a la red de agua potable, excepto en San Vicente, donde existe una cooperativa dedicada al servicio de agua potable, las demás localidades presentan un alto déficit en la capacidad de distribución. No existe sectorización, por lo tanto, cuando deben realizarse tareas de reparación el servicio se corta totalmente.

- Ninguna de las áreas urbanas de la región cuenta actualmente con servicios de cloacas y desagües cloacales. La gran mayoría de las calles asfaltadas de las localidades poseen importantes desniveles y no presentan los desagües pluviales necesarios para evacuar eficientemente el agua de las Iluvias; además, los residuos que esta arrastra se focalizan en sitios sin desnivel, causando contaminación. Algunas calles pavimentadas no cuentan con cordón cuneta. - En relación con los residuos sólidos urbanos, desde 1999 el transporte, tratamiento y disposición final de Residuos Sólidos Domiciliarios (RSD), Asimilables (RSA) y Patológicos (RP) se encuentra concesionado a la empresa AESA Misiones, responsable del sistema integral para el tratamiento de los residuos en toda la provincia. Actualmente, los municipios de la región no cuentan con una gestión y manejo adecuado de los RSU.

En general, las tres áreas urbanas carecen de reglamentaciones sobre usos de suelo. Predominan las edificaciones de planta baja; en muy pocos casos se superan los tres niveles de altura. Las tres localidades tienen su casco céntrico con una trama definida; sin embargo, la expansión de población que se ha producido en los últimos años se ha materializado en asentamientos irregulares, sin ningún tipo de ordenamiento territorial. Las áreas de alto valor paisajístico se encuentran abandonadas en su gran mayoría. Los espacios verdes públicos no cuentan con equipamientos para que la población y los turistas puedan recrearse. En El Soberbio la ocupación irregular genera discontinuidades en 
la trama urbana y se extiende hacia otros sectores, como por ejemplo en parte del área costera del río Uruguay o en el cerro Bonito, donde las condiciones topográficas dificultan aún más los problemas que ocasiona la escasez de infraestructura básica.

\section{CONCLUSIONES}

Tanto el Plan Estratégico Nacional y el Provincial de Turismo, como la Carta Orgánica Municipal de El Soberbio concuerdan en la necesidad de promover un modelo de desarrollo sustentable y ven en el turismo una oportunidad muy importante para viabilizar el desarrollo económico y social de la región. Sin embargo, existen importantes carencias y procesos actuales que se deben considerar para que esta actividad se desarrolle en beneficio de la sociedad local y la sustentabilidad ambiental.

Es fundamental que los gobiernos locales de la región, y en particular el de El Soberbio, crezcan en capacidades para gestionar y regular estas actividades con un sentido de promover el crecimiento endógeno, capitalizando para el ámbito local y regional partes de los excedentes de la actividad. Esta capacidad también se debe reflejar en el impulso de proyectos importantes de servicios, equipamientos e infraestructura social, para adecuar los territorios urbanos y rurales para un mejor nivel de vida de la población y de los visitantes. Ambas cosas están íntimamente relacionadas. No debe concebirse el desarrollo de la actividad pensando exclusivamente en la explotación de los recursos naturales, sino desde la perspectiva de su impacto en el desarrollo local.

En los últimos años, con el auge de un turismo alternativo del convencional, se ha comenzado a demandar una modalidad denominada ecoturismo, el cual debería contribuir a que el sector turístico en su conjunto sea más sostenible, acrecentando los beneficios económicos y sociales para la ciudad y la región e incrementando la sensibilización de los viajeros respecto de la conservación del patri- monio natural y cultural de las comunidades anfitrionas (DECLARACIÓN DE QUEBEC, 2002).

La región de los Saltos del Moconá cuenta con recursos naturales y culturales que representan una oportunidad para la integración de las zonas rurales a este tipo de turismo.

El perfil del visitante turista está dado actualmente por aquellos que buscan el contacto con la naturaleza, y los desarrollos de la infraestructura turística se están dando por emprendimientos en relación directa con la selva y los recursos acuíferos.

La zona de El Soberbio presenta un ecosistema sociocultural muy particular, con el predominio de población rural compuesta de pequeños productores minifundistas, comunidades originarias e inmigrantes, con una fuerte interacción fronteriza con Brasil y que está en proceso de trasformación debido a la migración de pobladores rurales pobres hacia los centros urbanos.

Este ecosistema es parte de las cualidades turísticas de la región, y debe promoverse su preservación. Para esto es necesario mejorar la calidad de vida en todos sus aspectos en las propias zonas rurales, para evitar la migración forzosa. Se debe profundizar la regulación de las actividades productivas rurales para preservar adecuadamente los recursos naturales en función de las actividades turísticas.

El Soberbio requiere un Plan de Desarrollo y Ordenamiento Urbano, que contemple el crecimiento informal que está teniendo, la provisión de equipamientos sociales, infraestructuras y servicios para mejorar la calidad de vida de la población, y que adecúe la ciudad a la actividad turística. Una planificación urbana que además contemple los espacios recreativos públicos y privados, contribuye a que los habitantes se identifiquen con su ciudad y la convierte en un atractor turístico. A través de estos lineamientos, la localidad de El Soberbio podrá convertirse en un centro estratégico turístico de la región de los Saltos del Moconá. 


\section{BIBLIOGRAFÍA}

CARDOSO, María Mercedes; FRITSCHY, Blanca Argentina (2012) Revisión de la definición del espacio rururbano y sus criterios de delimitación. En: Contribuciones Científicas GÆA, Vol. 24, Págs. 27-39 [En línea] [Consulta: 15 de junio de 2014] Disponible en: http://gaea.org.ar/contribuciones/ CONTRIBUCIONES_2012/4.GAEA\%20CONTRIBUCIONES_2012_CARDOSO.pdf.

CARTA ORGÁNICA MUNICIPAL DE EL SOBERBIO (1990). Misiones, Argentina.

CONSTITUCIÓN NACIONAL (1994) Santa Fe, Argentina.

CONSTITUCIÓN DE LA PROVINCIA DE MISIONES (1998) Posadas, Misiones, Argentina.

COSSIO, Luis Lira (2003) La cuestión regional y local en América Latina. Serie Gestión Pública 44, CEPAL, Naciones Unidas, Santiago de Chile.

DECLARACIÓN DE QUEBEC. Cumbre Mundial del Ecoturismo (2002) Quebec, Canadá.

DEMBICZ, Katarzyna (2005) "La región y el desarrollo regional en los conceptos socioeconómicos de la CEPAL", Centro de Estudios Latinoamericanos, Universidad de Varsovia.

DíAZ LACAVA, Amalia (2003) "Instrumentos para la planificación integral del uso de la tierra con sistemas de información geográfica - un caso de estudio en Argentina" En: http://edoc.hu-berlin.de/dissertationen/diaz-lacava-amalia-nahir-2003-07-16/HTML/chapter5.html

ESPEJO MARÍN, Cayetano (2003) "Anotaciones en torno al concepto de región", Revista NIMBUS N. ․ 11-12, Universidad de Almería, España.

CENSO NACIONAL DE POBLACIÓN, HOGARES Y VIVIENDAS. (2010) Instituto Nacional de Estadísticas y Censos. Argentina.

GARCÍA, Rolando (2006). Sistemas complejos. Conceptos, métodos y fundamentación epistemológica de la investigación interdisciplinaria. Barcelona, España: Gedisa.

LEY NACIONAL DE TURISMO N. ${ }^{\circ} 25997$ (2005) Buenos Aires, Argentina.

LEY N. ${ }^{\circ}$ 3631/99 CORREDORES VERDES DE LA PROVINCIA DE MISIONES (1999)

LEY PROVINCIAL DE ORDENAMIENTO Y CONSERVACIÓN DE BOSQUES NATIVOS DE MISIONES (2010).

MORIN, Edgar (1990). Introducción al pensamiento complejo. España: Gedisa Editorial.

PLAN ESTRATÉGICO SUSTENTABLE TURÍSTICO -PEST- DE LAS REGIONES DE LAS FRONTERAS Y DE LOS SALTOS DEL MOCONÁ (2012). Misiones, Argentina.

PLAN FEDERAL ESTRATÉGICO DE TURISMO SUSTENTABLE ARGENTINA 2016 (PFETS, 2006)

MERTINS, Günter (2003). "Desarrollo regional en América Latina bajo condiciones neoliberales: procesos - consecuencias - tendencias. Algunas observaciones generales". En: Actas Latinoamericanas de Varsovia, Tomo 26. Ed. Wydział Geografii i Studiów Regionalnych Uniwersytetu Warszawskiego, Varsobia.

ROCCATAGLIATA, Juan (Coord.) (2008) Argentina, una visión actual y prospectiva desde la dimensión territorial, EMECÉ, Buenos Aires.

Páginas de Internet

www.ambiente.gov.ar www.censo2010.indec.gov.ar edoc.hu-berlin.de elsoberbioturismo.blogspot.com www.politicassociales.gov.ar www.redyaguarete.org.ar www.scielo.org.ar www.turismo.misiones.gov.ar 